\title{
Anesthesia airway management for tracheal resection and reconstruction: a single-center case series
}

\author{
Xia Liu ${ }^{1 \#}$, Rong Jiang ${ }^{1 \#}$, Jie Xiao ${ }^{2 \#}$, Tao Lu ${ }^{3}$, Jiaqi Gan ${ }^{4}$, Jing Cheng ${ }^{1}$, Juan Liao $^{5}$, Peng Li $^{1 \wedge}$ \\ ${ }^{1}$ Department of Anesthesiology, Sichuan Provincial People's Hospital, University of Electronic Science and Technology of China, Chengdu, China; \\ ${ }^{2}$ Chengdu Medical College, Chengdu, China; ${ }^{3}$ Department of Radiology, Sichuan Provincial People's Hospital, University of Electronic Science and \\ Technology of China, Chengdu, China; ${ }^{4}$ Department of Anesthesiology, Sichuan Provincial Maternity and Child Health Care Hospital, Chengdu, \\ China; ${ }^{5}$ Department of Stomatology, Sichuan Provincial People's Hospital, University of Electronic Science and Technology of China, Chengdu, \\ China \\ Contributions: (I) Conception and design: P Li; (II) Administrative support: R Jiang, J Liao; (III) Provision of study materials or patients: X Liu; (IV) \\ Collection and assembly of data: X Liu, J Xiao, J Gan; (V) Data analysis and interpretation: T Lu, J Cheng; (VI) Manuscript writing: All authors; (VII) \\ Final approval of manuscript: All authors. \\ \#These authors contributed equally as first author. \\ Correspondence to: Peng Li, PhD, MD. Sichuan Provincial People's Hospital, University of Electronic Science and Technology of China, Chengdu, \\ 610072, China. Email: lipengmazui@qq.com; Juan Liao, PhD, MD. Department of Stomatology, Sichuan Provincial People's Hospital, University of \\ Electronic Science and Technology of China, Chengdu 610072, China. Email: 109497731@qq.com.
}

Background Anesthesia airway management is challenging during tracheal resection and reconstruction
as these surgical procedures involve the airway. This case series describes four approaches to airway
management in patients undergoing tracheal resection and reconstruction and discusses their advantages and
disadvantages.

Methods: Thirteen patients underwent 1 of the following 4 kinds of airway management techniques during tracheal resection and reconstruction between 2013 and 2019: intubation, intubation with high frequency jet ventilation (HFJV), non-intubation, and venovenous extracorporeal membrane oxygenation (VV-ECMO). Intraoperative variables and postoperative outcomes were compared for the techniques based on our institution's medical electronic database.

Results: Intraoperative oxygenation management involved VV-ECMO in 8 patients, intubation in 2 patients, intubation with HFJV in 2 patients, or non-intubation in 1 patient. The lowest peripheral oxygen saturation $\left(\mathrm{SpO}_{2}\right)$ in 4 patients was below $90 \%$. Three patients were extubated in the operation room after complete recovery of spontaneous respiration. Most patients were admitted to the intensive care unit for further postoperative treatment, except 1 patient who received laryngeal mask airway management without tracheal intubation during surgery. Two patients died, 1 due to severe anastomotic leakage and the other from acute respiratory distress syndrome. In addition, another patient showed complications with oozing from the wound.

Conclusions: Our clinical experience suggests that there is no single airway strategy universally suitable for all tracheal surgeries. The choice of airway management strategy is best determined by multifactorial assessment of advantages and disadvantages according to preoperative comorbidities, unique features of the obstructive mass, surgical experience, and patient preference.

Keywords: Airway management; tracheal resection and reconstruction; intubation; high frequency jet ventilation (HFJV); extracorporeal membrane oxygenation

Submitted Jan 27, 2021. Accepted for publication Mar 22, 2021.

doi: $10.21037 /$ apm-21-431

View this article at: http://dx.doi.org/10.21037/apm-21-431

\footnotetext{
$\wedge$ ORCID: 0000-0002-5097-3244.
} 


\section{Introduction}

Tracheal stenosis, a narrowing of the trachea, may occur secondary to trauma, tumors, infections, and inflammatory or iatrogenic diseases (1-3). The most common symptoms of inspiratory airway obstruction include coughing, expectoration, shortness of breath, stridor, and paroxysmal dyspnea, which can worsen after exertional activity (3). Tracheal resection and reconstruction are the predominant palliative or radical treatments for severe airway obstruction $(1,4)$. Surgery may improve 5 -year survival rates from $5 \%$ to $47 \%$ (5). However, anesthesia during upper airway surgery is challenging as both anesthesiologists and surgeons are focused on the airway, and maintaining ventilation during general anesthesia is difficult (6-8). If ventilation cannot be effectively established after induction of general anesthesia, the patient's life may be endangered (9).

Methods for airway management depend mainly on the nature, location, and growth pattern of the obstructive mass, as well as the degree of airway obstruction and the surgical approach (10-12). Different techniques for airway management have been applied during upper airway surgery (3,13-15), such as intubation (3), intubation with high frequency jet ventilation (HFJV) (13), nonintubation (14), and venovenous extracorporeal membrane oxygenation (VV-ECMO) (15). One previous review adequately described their institution's experiences with the intubation technique of airway management for various operations for tracheal resection and reconstruction (16). Another previous article found that jet ventilation offered better exposure of the surgical field compared to an endotracheal tube, and spontaneous ventilation was preferable for patients with critical airway obstruction (3). Nevertheless, not much fully discussed four different airway management methods and compared the advantages and disadvantages at the same time when dealing with severe airway obstruction.

Due to lack of prospective controlled studies systematically comparing various methods of anesthetic management (16), we are still unaware how to choose the most suitable airway management during surgery for severe airway obstruction. In order to expand the research basis for comparing airway management methods, we describe here our experiences with 13 patients who underwent tracheal resection and reconstruction at our hospital using different approaches for airway management. We present the following article in accordance with the STROBE reporting checklist (available at http://dx.doi.org/10.21037/apm-21-431).

\section{Methods}

\section{Study population}

This retrospective study was approved by the Ethics Committee of the Sichuan Academy of Medical Sciences and Sichuan Provincial People's Hospital (Chengdu, China), and informed consent was waived. All procedures performed in this study involving human participants were in accordance with the Declaration of Helsinki (as revised in 2013) (17). The study included 13 patients who underwent tracheal resection and reconstruction between March 2013 and July 2019 at Sichuan Provincial People's Hospital. Each patient received 1 of the following 4 kinds of airway management techniques: intubation, intubation with HFJV, non-intubation, or VV-ECMO.

\section{Surgical procedures}

Eight patients received VV-ECMO in the operating room before induction of anesthesia. Patients received injections of low-dose dexmedetomidine and midazolam for sedation, and $2000 \mathrm{U}$ heparin infusion as an anticoagulant. Next, the interventionalist introduced $21 \mathrm{Fr}$ cannulation in the inferior vena cava for outflow from the femoral vein and $17 \mathrm{Fr}$ cannulation in the right atrium for inflow from the internal jugular vein under local anesthesia. ECMO flows were set at 3-4 L/min with $100 \%$ oxygen, and the rates were adjusted based on the status of oxygenation and ventilation. When the pulse oximetry, arterial blood gas analysis, and arterial blood pressure remained within normal ranges, the $\mathrm{VV}$ ECMO was considered effective. After the establishment of VV-ECMO, patients were gradually anesthetized using propofol $(2-2.5 \mathrm{mg} / \mathrm{kg})$ in combination with sufentanil $(0.4 \mu \mathrm{g} / \mathrm{kg})$, and cisatracurium $(0.15-0.2 \mathrm{mg} / \mathrm{kg})$. Intraoperatively, propofol, remifentanil, and cisatracurium were administered intravenously to maintain anesthesia. When spontaneous breathing totally disappeared with a bispectral index (BIS) of 40-60, oxygenation was performed using VV-ECMO. Ventilation was not performed until tracheal reconstruction was completed, at which point orotracheal intubation was performed to avoid postoperative blockage of the airway which might have been due to postoperative bleeding or anastomotic leakage. In addition, we visually confirmed, using a fiber bronchoscope, that the cuff of the endotracheal tube did not compress the 
A

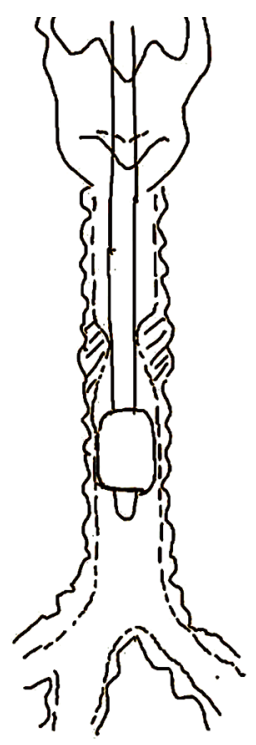

B

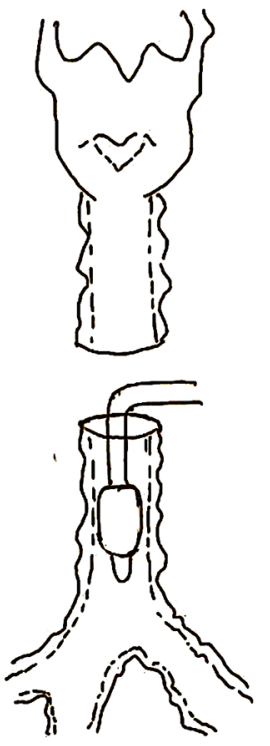

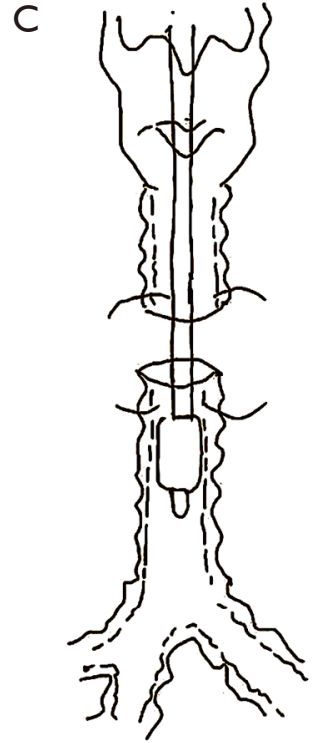

Figure 1 Scheme of the intubation procedure for airway management during tracheal resection and reconstruction. (A) Oral endotracheal intubation with the tip and cuff of the tube across the stenotic segment; (B) after tracheal incision, a sterile circuit is placed in the distal airway for mechanical ventilation during resection of the stenotic segment; (C) the return to oral intubation during anastomosis with the tip and cuff located distal to the anastomosis.

anastomosis site. The mode of pressure control ventilation was adopted during mechanical ventilation. The pressure was adjusted according to tidal volume during the operation. After finishing suturing the trachea, we maintained the airway pressure below $30 \mathrm{cmH}_{2} \mathrm{O}$. When the patients were fully conscious with respiratory recovery after surgery, they were weaned off ECMO and extubated.

Two patients underwent intubation after anesthesia induction. The general anesthesia for these 2 patients was induced by propofol $(2-2.5 \mathrm{mg} / \mathrm{kg})$ in combination with sufentanil $(0.4 \mu \mathrm{g} / \mathrm{kg})$ and succinylcholine $(1-1.5 \mathrm{mg} / \mathrm{kg})$ after positive pressure ventilation was confirmed successfully via face mask. The cuff of the 2 patients was placed below the level of stenosis in order to isolate the blood or abscission tissue from the mass. Propofol, remifentanil, and cisatracurium were administered intravenously to maintain sufficient depth of anesthesia. Volume-controlled ventilation mode was adopted with a tidal volume of $6-8 \mathrm{~mL}$ and frequency of 12-18 times/min, according to the arterial partial pressure of carbon dioxide. After the surgeon incised the tracheal wall, the orotracheal tube was removed and a sterile endotracheal tube was inserted into the distal trachea of the lesion to facilitate mechanical ventilation (Figure 1). After the diseased trachea was removed and the posterior wall of the trachea was sutured, the tip of the orotracheal tube was inserted beyond the anastomotic site under direct vision. The surgeons then finished suturing and confirmed no air leakage. The orotracheal tube was not removed until patients showed stable vital signs and had completely recovered spontaneous breathing.

In 2 patients, HFJV rather than a sterile endotracheal tube was used for intubation after the surgeon had made an incision in the trachea. Anesthesia induction and maintenance were similar to those for the abovementioned 2 patients. The driving pressure of HFJV was approximately 1.5 bar and the frequency was 200 times per minute in order to maintain oxygenation and provide good surgical conditions. At the end of the reconstruction, the HFJV catheter was removed and positive pressure ventilation was applied through the orotracheal tube (Figure 2). The pressure control mode was adopted during mechanical ventilation, and pressure was adjusted according to tidal volume intraoperatively. After the orotracheal tube was placed below the anastomotic site, the airway pressure was controlled below $30 \mathrm{cmH}_{2} \mathrm{O}$.

One patient was selected for non-intubation anesthesia. After induction of general anesthesia, a size 3 laryngeal mask was inserted without infusing muscle relaxants. In order to reduce the dosage of general anesthetics, which can inhibit spontaneous breathing, the awake patient received T6-T7 epidural anesthesia with epidural catheter insertion. 

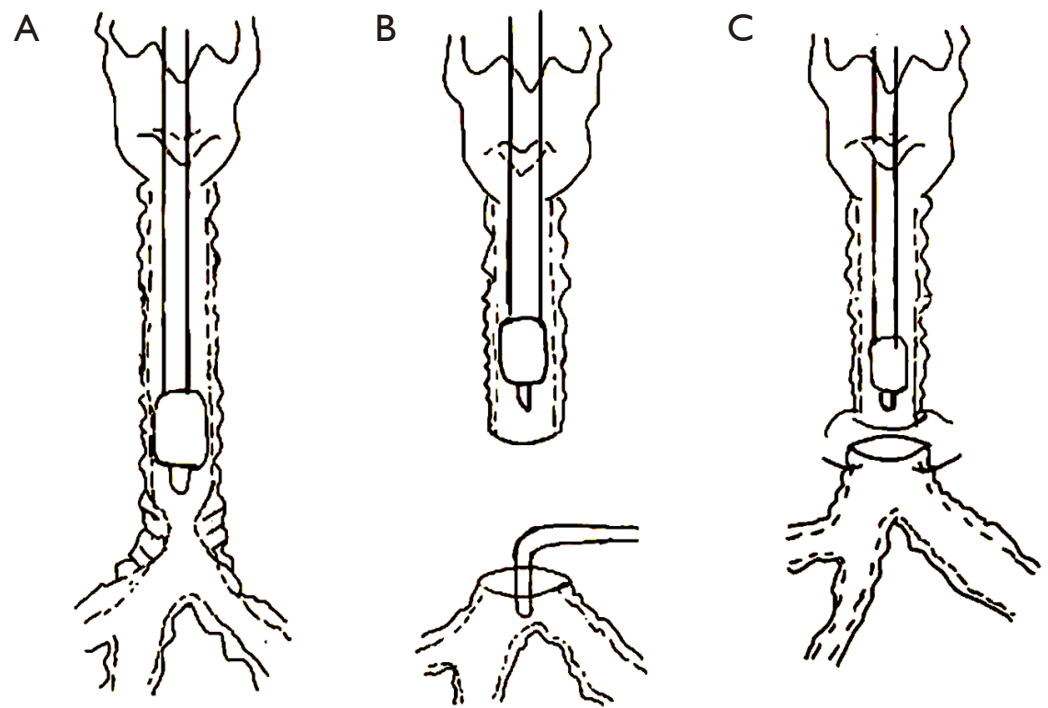

Figure 2 Scheme of the intubation and high frequency jet ventilation procedure for anesthesia airway management during tracheal resection and reconstruction. (A) Oral endotracheal intubation with the tip of the tube above the stenotic segment; (B) after tracheal incision, a sterile high frequency jet ventilation tube is placed in the distal airway during resection and anastomosis; (C) the return to oral intubation after anastomosis.

After injection of $3 \mathrm{~mL}$ of $2 \%$ lidocaine for testing, the patient was injected with $7 \mathrm{~mL}$ of $0.75 \%$ ropivacaine via the epidural catheter. After the anesthesia plane was determined to be T2-T10, propofol and remifentanil were titrated to induce anesthesia while preserving spontaneous ventilation. Propofol and remifentanil were administered in target-controlled infusion (TCI), with the propofol plasma concentration increasing at $1.0 \mu \mathrm{g} / \mathrm{mL}$ and the remifentanil plasma concentration increasing at $1.0 \mathrm{ng} / \mathrm{mL}$. When the BIS was below 60, a size 3 laryngeal mask was inserted. In order to avoid an apneic response, the BIS was maintained between $50-60$ by TCI, with a propofol plasma concentration of $3-4 \mu \mathrm{g} / \mathrm{mL}$ and remifentanil plasma concentration of $2-3 \mathrm{ng} / \mathrm{mL}$ during the surgery. In addition, surgeons sprayed $2 \%$ lidocaine $(5 \mathrm{~mL})$ on the surface of the lungs and blocked the right vagus in the thorax with $0.375 \%$ ropivacaine $(5 \mathrm{~mL})$ during thoracoscopic surgery to prevent the cough reflex from interfering with surgical procedures. Spontaneous respiration was maintained throughout the operation. After the surgeons incised the trachea, the distal trachea was elevated to ensure that blood and secretions from the chest could not cause aspiration during spontaneous breathing. A sterile oxygen tube was placed near the proximal trachea to increase the concentration of oxygen in the inhaled gas. After the trachea was sutured, the sterile oxygen tube was removed and the patient breathed through a laryngeal mask airway.

\section{Patient data collection}

Demographic and clinical data were obtained from the institution's electronic database, including sex, age, height, weight, body mass index (BMI), American Society of Anesthesiologists (ASA) physical status, and degree of airway obstruction, as well as the nature, size, and location of the obstructive mass.

\section{Statistical analysis}

We used SPSS 24.0 (IBM, Chicago, IL, USA) for statistical analysis. Results were reported as median and range (minimum-maximum), or as absolute numbers (n).

\section{Results}

\section{Patient demographics}

Patients who received tracheal resection in our cohort were mostly middle-aged females with normal BMI (Table 1). In 1 patient, with mask oxygen inhalation in the ward, the lowest oxygen saturation in blood was $88 \%$. About half of these patients had an ASA status of III. The most common 
Table 1 Baseline demographic and clinical characteristics of patients $(\mathrm{n}=13)$

\begin{tabular}{lc}
\hline Characteristic & Median [range] or $\mathrm{n}$ \\
\hline Age (years) & $45[21-65]$ \\
Weight $(\mathrm{kg})$ & $60[41-84]$ \\
Height $(\mathrm{m})$ & $1.67[1.51-1.74]$ \\
$\mathrm{BMI}\left(\mathrm{kg} / \mathrm{m}^{2}\right)$ & $21.5[17.4-31.6]$ \\
Preoperative $\mathrm{SpO}_{2}$ (with oxygen) & $96[88-99]$ \\
Sex & \\
Male & 8 \\
Female & 5 \\
ASA physical status & \\
II & 4 \\
III & 7 \\
IV & 2 \\
Preoperative exertion dyspnea & 10 \\
Preoperative stridor at rest & 8 \\
Preoperative respiratory failure & 3 \\
\hline Values are absolute numbers & \\
\hline
\end{tabular}

Values are absolute numbers ( $n$ ) or median and range (minimum-maximum). BMI, body mass index; $\mathrm{SpO}_{2}$ peripheral oxygen saturation; ASA, American Society of Anesthesiologists.

symptoms before surgery were exertion dyspnea $(n=10)$ and stridor at rest $(\mathrm{n}=8)$.

\section{Characteristics of the obstructive mass}

The most prevalent causes of tracheal stenosis were primary tracheal tumors (Table 2). Tracheal tumors were mostly adenoid cystic carcinomas $(n=5)$, followed by mucoepidermoid carcinoma $(n=3)$, and squamous cell carcinoma $(n=1)$. The reasons for tracheal stenoses in the other 4 patients were traumatic factors $(n=2)$, prolonged mechanical ventilation $(\mathrm{n}=1)$, and tracheostomy $(\mathrm{n}=1)$. The stenoses were situated at a median distance of $4.5 \mathrm{~cm}(1.4$ $9.0 \mathrm{~cm})$ from the vocal cords or $5.2 \mathrm{~cm}(1.5-9.3 \mathrm{~cm})$ from the carina. The median level of tracheal stenosis was $75 \%$ (30-96\%). The median length of tracheal resection was $2.0 \mathrm{~cm}(1.5-3.0 \mathrm{~cm})$.

\section{Intraoperative data}

Twelve patients were monitored for invasive blood pressure,
Table 2 Characteristics of the obstructive mass and approaches for airway management $(n=13)$

\begin{tabular}{|c|c|}
\hline Characteristic & Median (range) or $\mathrm{n}$ \\
\hline Maximum CSA $\left(\mathrm{cm}^{2}\right)$; length $\times$ width $(\mathrm{cm})$ & $\begin{array}{c}1.80(0.88-4.14) \\
1.2 \times 1.5(1.1 \times 0.8-2.3 \times 1.8)\end{array}$ \\
\hline Distance from vocal cords $(\mathrm{cm})$ & $4.5(1.4-9.0)$ \\
\hline Distance from carina $(\mathrm{cm})$ & $5.2(1.5-9.3)$ \\
\hline Tracheal stenosis level (\%) & 75 [30-96] \\
\hline Tracheal resection length $(\mathrm{cm})$ & $2.0(1.5-3.0)$ \\
\hline \multicolumn{2}{|l|}{ Cause of tracheal obstruction } \\
\hline Primary tracheal tumor & 9 \\
\hline Squamous cell carcinoma & 1 \\
\hline Adenoid cystic carcinoma & 5 \\
\hline Mucoepidermoid carcinoma & 3 \\
\hline Traumatic & 2 \\
\hline Post-intubation & 1 \\
\hline Tracheostomy & 1 \\
\hline \multicolumn{2}{|l|}{ Approach for airway management } \\
\hline Intubation & 2 \\
\hline Intubation with HFJV & 2 \\
\hline Non-intubation & 1 \\
\hline VV-ECMO & 8 \\
\hline
\end{tabular}

Values are absolute numbers $(n)$ or median and range (minimum-maximum). CSA, cross-sectional area; HFJV, high frequency jet ventilation; VV-ECMO, venovenous extracorporeal membrane oxygenation.

of whom 6 received central venous catheterization. The median time for anesthesia was $260 \mathrm{~min}$, and the median operation time was $235 \mathrm{~min}$ (Table 3). The median estimated blood loss was $160 \mathrm{~mL}$, and the median volume of fluid infusion was $1,700 \mathrm{~mL}$. Among all the patients, the lowest $\mathrm{SpO}_{2}$ in 4 patients (patients 3, 5, 9, and 10) was below $90 \%$. Patient 3, who was managed using intubation with HFJV, was under anesthesia for the longest time (470 $\mathrm{min}$ ) and also underwent the longest surgery $(445 \mathrm{~min})$. This patient also suffered the highest blood loss $(1,200 \mathrm{~mL})$, and received the highest volume of fluid transfusion $(5,000 \mathrm{~mL})$. In the comparison of the lowest $\mathrm{SpO}_{2}$ and peak end-tidal dioxide pressure during the operation among all patients, patient 3 had the lowest $\mathrm{SpO}_{2}(74 \%)$ and the highest end-tidal dioxide pressure $(111 \mathrm{mmHg})$. Conversely, patient $13 \mathrm{had}$ the highest $\mathrm{SpO}_{2}(99 \%)$ and the lowest end-tidal dioxide 
Table 3 Intraoperative data $(\mathrm{n}=13)$

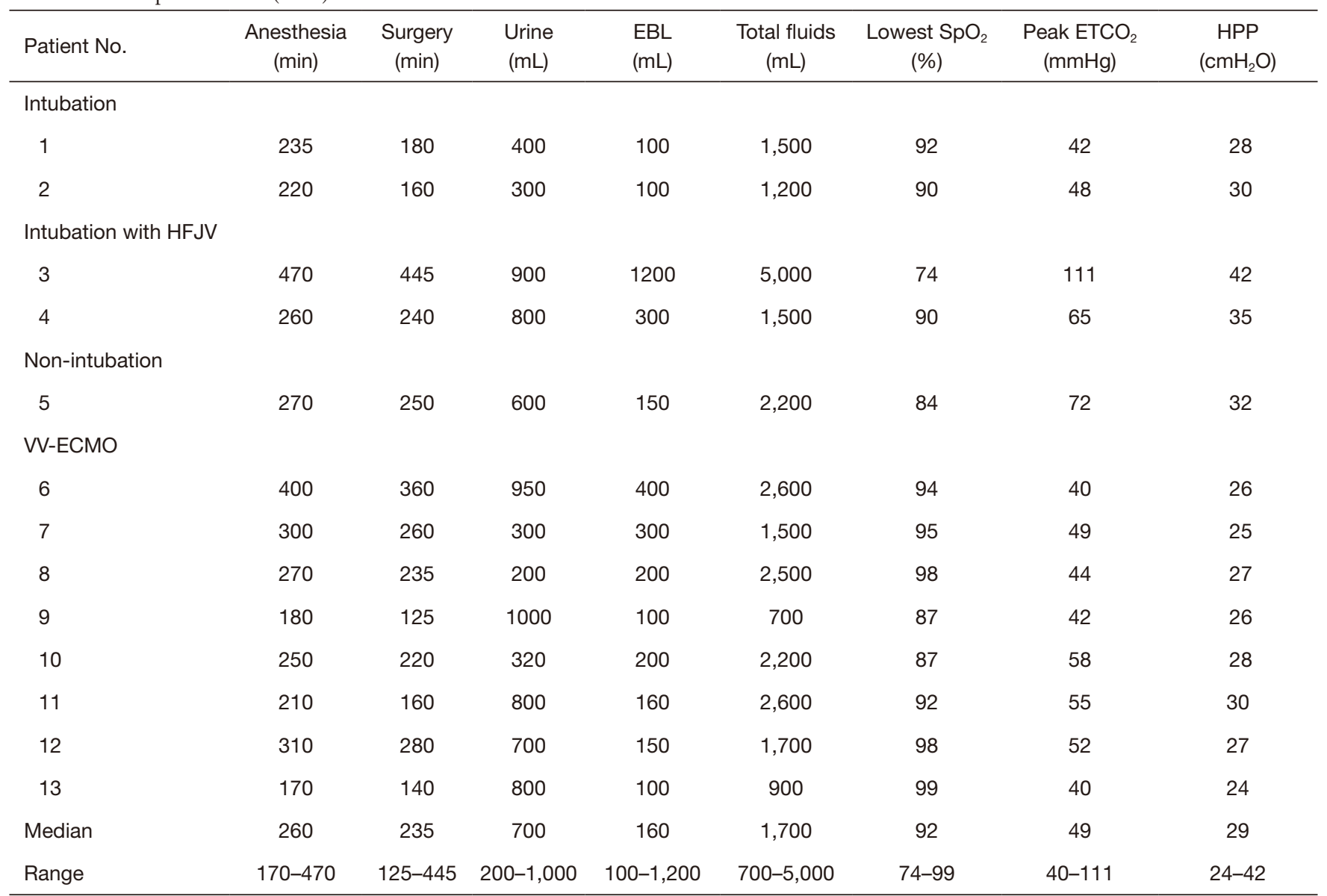

Values are absolute numbers ( $\mathrm{n}$ ) or median and range (minimum-maximum). EBL, estimated blood loss; $\mathrm{SpO}_{2}$, peripheral oxygen saturation; $\mathrm{ETCO}_{2}$, end-tidal carbon dioxide; HPP, highest peak pressure; HFJV, high frequency jet ventilation; VV-ECMO, venovenous extracorporeal membrane oxygenation.

pressure $(40 \mathrm{mmHg})$.

\section{Postoperative course}

Three patients (patients 2, 3, and 5) were extubated in the operation room after complete recovery of spontaneous respiration (Table 4). Most patients were admitted to the intensive care unit (ICU) for postoperative monitoring and treatment, except patient 5 , who was managed with a laryngeal mask during surgery and released directly back onto the ward. Patient 3 died on the third postoperative day and showed severe anastomotic leakage, while patient 10 died on the seventh postoperative day from acute respiratory distress syndrome. Patient 7 received 2 units of plasma and 2 units of erythrocyte suspension due to oozing from the wound. After excluding the 2 dead patients from the analysis, we found that the median postoperative hospitalization was 8 days (5-12 days). Furthermore, we observed that the postoperative hospital stay for patients who received VV-ECMO (8.57 days) tended to be longer than for other patients (7 days), though this difference did not achieve statistical significance.

\section{Discussion}

Anesthesia airway management plays a significant role in ensuring the safety of patients undergoing tracheal resection and reconstruction. There is no consensus on the optimal airway strategy for tracheal surgeries, and our experience with the 13 patients described in this study suggests that no single strategy is appropriate. Instead, the strategy should be chosen based on the state and preference of the patient, 
Table 4 Postoperative data $(\mathrm{n}=13)$

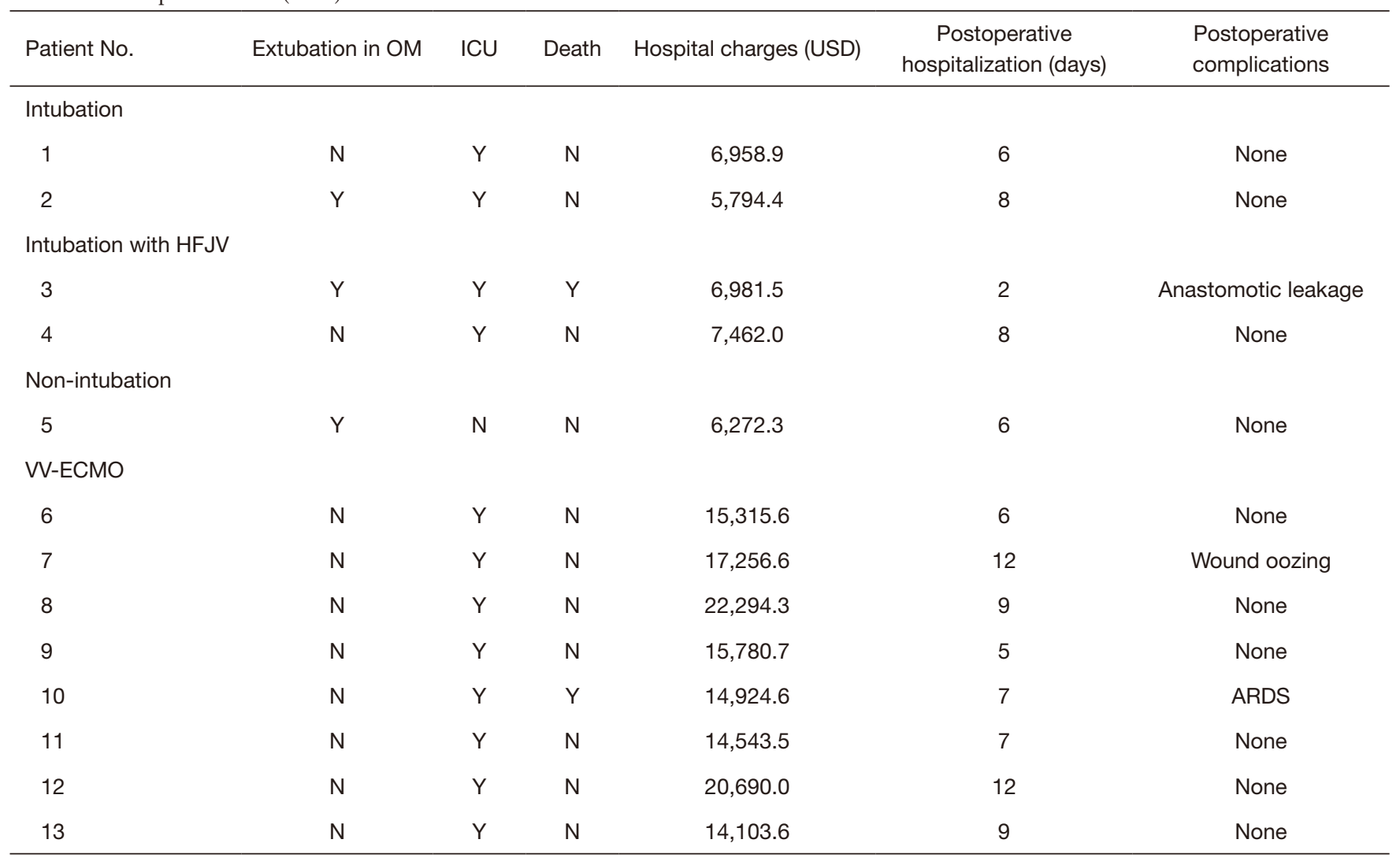

ARDS, acute respiratory distress syndrome; ICU, intensive care unit; OM, operation room; USD, USA dollar (the exchange rate between US dollar and RMB is 1:6.5); N, no; Y, yes. HFJV, high frequency jet ventilation; VV-ECMO, venovenous extracorporeal membrane oxygenation.

the experience of the surgeons, the surgical methods, and the equipment of anesthesia.

The important factor for airway management is clinical evaluation. In our study, most patients presented exertional dyspnea and stridor at rest. Exertion dyspnea appears when the tracheal diameter is narrowed by more than $50 \%$ or to a final value of $8 \mathrm{~mm}(18,19)$. When the internal diameter falls below 5-6 mm, patients present with stridor at rest (20). To formulate the most appropriate anesthesia plan, we carefully assessed preoperative symptoms and used highresolution, three-dimensional computed tomography (CT) and fiber-optic bronchoscopy to assess the nature, growth pattern, and location of the obstructive mass, the degree of airway obstruction, and the distance from the vocal cords and carina (21). We also determined in which position the patient was most comfortable and the patient's airway is least likely to be obstructed after induction of anesthesia (22). We communicated with surgeons about the patients' pulmonary function, length of tracheal resection, and any areas of tracheomalacia or tracheal inflammation (3).

In our study, the levels of airway obstruction and the tracheal diameters of the 2 patients with intubation (patients 1 and 2) were $70 \%(6 \mathrm{~mm})$ and $55 \%(8 \mathrm{~mm})$. As demonstrated in a previous case report (7), the anesthesia plan for endotracheal intubation is suitable for patients with soft or mild tracheal stenosis. In our cases, the level of tracheal stenosis was below $75 \%$ with the unobstructed tracheal diameter beyond $5 \mathrm{~mm}$, which could ensure sufficient space to intubate with the endotracheal tube. Moreover, the mass was not prone to bleeding or detachment. Otherwise, endotracheal intubation may result in tumor fragmentation or bleeding, which may aggravate tracheal stenosis. However, even a small-caliber endotracheal tube placed in the distal tracheal lesion can reduce visibility of the surgical field during anastomosis.

The stenoses of 2 patients (patients 3 and 4) were situated 


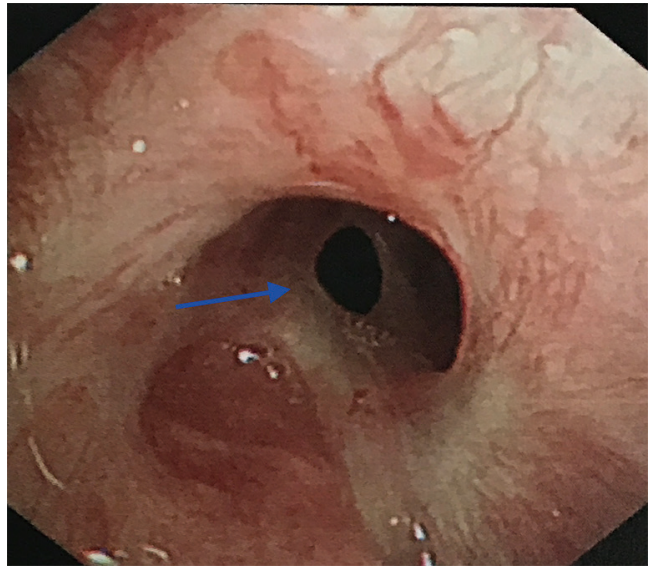

Figure 3 Bronchoscopy view of 1 patient (patient 5) with postintubation tracheal stenosis who underwent non-intubation anesthesia. The arrow indicates the narrowest part of the trachea with a diameter of $3 \mathrm{~mm}$.

at distances of 0.5 and $1.5 \mathrm{~cm}$ from the carina, with maximum cross-section areas of $2.1 \times 2.8$ and $2.3 \times 1.8 \mathrm{~cm}^{2}$. Due to the proximity of the stenosis to the carina, endotracheal intubation at the carina affects the surgical anastomosis of the trachea. Since ECMO technology was unavailable at our hospital in 2013, we used an HFJV catheter instead of an endotracheal tube because the tumor was large and close to the carina. The HFJV catheter interfered less with the anastomosis than an endotracheal tube intubation would have. However, we found that the 2 patients with the HFJV catheter required longer anesthesia and surgery than the 2 patients who received endotracheal intubation. The reason may be that the tumor location was close to the carina, which makes surgical anastomosis difficult.

The 2 patients with the HFJV catheter showed an obvious buildup of carbon dioxide during anastomosis. Patient 3 presented the lowest $\mathrm{SpO}_{2}$ level of $74 \%$ and a peak end-tidal carbon dioxide level of $111 \mathrm{mmHg}$ during surgery. This patient showed postoperative complications with anastomotic leakage, which might have been due to the length of tracheal resection $(3.0 \mathrm{~cm})$, wind-induced contusion by the HFJV, and high stretching tension at the anastomotic site. The patient ultimately died after the family refused further surgery-related treatment and left the hospital against medical advice. We conclude that HFJV may worsen intra- and postoperative outcomes, although the poor outcomes of our patient might have been due to the more difficult surgery because of the tumor location. Nevertheless, HFJV may allow for greater visibility of the surgical field than distal tracheal intubation (3), and can support ventilation in rescue situations (22). Further work should examine the advantages of HFJV in different types of patients.

A previous case report summarized the indications for non-intubated spontaneous respiration anesthesia as follows: (I) no contraindications for anesthesia or surgery; (II) no severe cardiopulmonary diseases; and (III) low airway secretions (4). In the present case series, the patient with non-intubation (patient 5) was 28 years old, had a BMI of $18 \mathrm{~kg} / \mathrm{m}^{2}$, and did not have severe cardiopulmonary diseases. Tracheal stenosis was due to endotracheal intubation injury 3 months before. The tracheal scarring stenosis was followed by a chronic inflammatory reaction, granulation tissue formation, and subsequent fibrous scar formation owing to prolonged mechanical ventilation in the ICU. The level of airway obstruction was more than $90 \%$, and the narrowest tracheal diameter of the patient was $3 \mathrm{~mm}$ (Figure 3). Although the patient presented transient hypoxia and hypercapnia during the operation, she was extubated 5 minutes after the operation in the operating room. She did not require transfer to the ICU after surgery, and no complications were recorded. Her rapid recovery from the anesthesia was attributed to the accuracy of anesthetic depth monitoring and the absence of muscle relaxants (14). In this case, the greatest advantage of nonintubation was good visibility of the surgical field during reconstruction. Consistent with our experience, a singlecenter retrospective analysis showed that supraglottic airway devices for cervical tracheal resection and reconstruction were appropriate for patients diagnosed with scar tissue in the stenotic area and with anticipated difficult transstenotic tube placement (22). Based on that study and our own experience, we suggest that non-intubation may be a feasible, relatively safe airway management method for patients with (I) BMI $<25 \mathrm{~kg} / \mathrm{m}^{2}$, (II) less risk of airway secretion and bleeding, and (III) tracheal scarring stenosis who (IV) do not have severe cardiopulmonary dysfunction and (V) for whom transstenotic tube intubation is expected to be difficult.

Previous studies have suggested that ECMO can provide sufficient ventilation and oxygenation during surgery, and is especially suitable for critical patients with severe airway obstruction or when extensive resection of the infiltrating tumor is needed $(14,21,23)$. In our study, $\mathrm{SpO}_{2}$ was maintained above $90 \%$ in 6 out of 8 patients who received ECMO. In the other 2 patients, it dropped to $87 \%$ for approximately $10 \mathrm{~min}$. Similar to patients with a laryngeal mask, those on ECMO do not require airway 
tubing in the surgical field, which improves surgical field visibility during reconstruction of the posterior trachea (21). However, our patients who received ECMO had to stay in hospital marginally longer and take on higher hospital costs than the other patients. A previous study linked ECMO to various complications, including high hospital costs, bleeding caused by heparin, infection related to cannulation, thromboembolism, and lower limb ischemia (24). In our study, 1 patient with ECMO (patient 7) presented oozing from the wound as a result of a coagulation disorder. The patient received 2 units of plasma and 2 units of erythrocyte suspension transfusion and recovered on postoperative day 3. Another patient who underwent ECMO (patient 10) died of acute lung injury. The respiratory failure of the patient was most likely the result of a preexisting advanced pulmonary infection.

Our study presents several limitations. The first is the small number of patients analyzed, which could limit our conclusions regarding the benefits and limitations of the 4 airway management strategies. Secondly, as a retrospective study, post-discharge data, such as fiberoptic bronchoscopy images, clinical symptom and quality of life improvements, and long-term survival, were not collected.

Despite these limitations, our case series offers additional experiences to guide airway management planning for tracheal resection and reconstruction surgery. Tracheal resection and reconstruction require multidisciplinary collaboration involving surgical, anesthesia, interventional, and ICU teams. Airway strategies should be tailored to preoperative comorbidities, unique features of the obstructive mass, surgical experience, and patient consent.

\section{Acknowledgments}

Funding: Science and Technology Plan Project of Sichuan Province, China (2019YJS0221). Sichuan Provincial People's Hospital Institute Research Fund, China (2017YL18).

\section{Footnote}

Reporting Checklist: The authors have completed the STROBE reporting checklist. Available at http://dx.doi. org/10.21037/apm-21-431

Data Sharing Statement: Available at http://dx.doi. org/10.21037/apm-21-431

Conflicts of Interest: All authors have completed the ICMJE uniform disclosure form (available at http://dx.doi. org/10.21037/apm-21-431). The authors have no conflicts of interest to declare.

Ethical Statement: The authors are accountable for all aspects of the work in ensuring that questions related to the accuracy or integrity of any part of the work are appropriately investigated and resolved. All procedures performed in this study involving human participants were in accordance with the Declaration of Helsinki (as revised in 2013). This retrospective study was approved by the Ethics Committee of the Sichuan Academy of Medical Sciences and Sichuan Provincial People's Hospital (Chengdu, China), and informed consent was waived.

Open Access Statement: This is an Open Access article distributed in accordance with the Creative Commons Attribution-NonCommercial-NoDerivs 4.0 International License (CC BY-NC-ND 4.0), which permits the noncommercial replication and distribution of the article with the strict proviso that no changes or edits are made and the original work is properly cited (including links to both the formal publication through the relevant DOI and the license). See: https://creativecommons.org/licenses/by-nc-nd/4.0/.

\section{References}

1. Li F, Liang J, Li X. Resection and Reconstruction of the Trachea for the Treatment of Upper Tracheal Stenosis: Tracheal Versus Non-Tracheal Intubation. J Coll Physicians Surg Pak 2018;28:879-81.

2. Farzanegan R, Feizabadi M, Ghorbani F. An overview of tracheal stenosis research trends and hot topics. Arch Iran Med 2017;20:598-607.

3. Hobai IA, Chhangani SV, Alfille PH. Anesthesia for tracheal resection and reconstruction. Anesthesiol Clin 2012;30:709-30.

4. Huang J, Qiu Y, Chen L, et al. Nonintubated Spontaneous Respiration Anesthesia for Tracheal Glomus Tumor. Ann Thorac Surg 2017;104:e161-3.

5. Regnard JF, Fourquier P, Levasseur P. Results and prognostic factors in resections of primary tracheal tumors: a multicenter retrospective study. The French Society of Cardiovascular Surgery. J Thorac Cardiovasc Surg 1996;111:808-13.

6. Agarwal V, Parab SY, Pramesh CS. Protective Lung Strategy During Bronchoscopic Laser Resection of Tracheobronchial Tumors: A Case Series. J Cardiothorac 
Vasc Anesth 2017;31:2161-6.

7. Kawaraguchi Y, Taniguchi A. Anesthetic management of a 9-year-old child undergoing resection of a tracheal tumor. Paediatr Anaesth 2005;15:512-4.

8. Cho AR, Kim HK, Lee EA, et al. Airway management in a patient with severe tracheal stenosis: bilateral superficial cervical plexus block with dexmedetomidine sedation. J Anesth 2015;29:292-4.

9. Wendi C, Zongming J, Zhonghua C. Anesthesia airway management in a patient with upper tracheal tumor. J Clin Anesth. 2016;32:134-6.

10. Fritzsche K, Osmers A. Anesthetic management in laryngotracheal surgery. High-frequency jet ventilation as strategy for ventilation during general anesthesia. Anaesthesist 2010;59:1051-61.

11. Ahern BJ, Parente EJ. Surgical complications of the equine upper respiratory tract. Vet Clin North Am Equine Pract 2008;24:465-84.

12. Rena O, Maggi G, Oliaro A, et al. Upper trachea sleeve resection and anastomosis for invasive thyroid carcinoma. Eur J Cardiothorac Surg 2004;26:459-60.

13. Dzuberová I, Sabaková L, Juráková O, et al. High frequency jet ventilation in trachea reconstructions-its advantages in our experience. Acta Chir Hung 1999;38:31-4.

14. Li S, Liu J, He J, et al. Video-assisted transthoracic surgery resection of a tracheal mass and reconstruction of trachea under non-intubated anesthesia with spontaneous breathing. J Thorac Dis 2016;8:575-85.

15. Dunkman WJ, Nicoara A, Schroder J, et al. Elective Venovenous Extracorporeal Membrane Oxygenation for Resection of Endotracheal Tumor: A Case Report. A A Case Rep 2017;9:97-100.

Cite this article as: Liu X, Jiang R, Xiao J, Lu T, Gan J, Cheng J, Liao J, Li P. Anesthesia airway management for tracheal resection and reconstruction: a single-center case series. Ann Palliat Med 2021;10(3):3354-3363. doi: 10.21037/apm$21-431$
16. Sandberg W. Anesthesia and airway management for tracheal resection and reconstruction. Int Anesthesiol Clin 2000;38:55-75.

17. World Medical Association. World Medical Association Declaration of Helsinki: ethical principles for medical research involving human subjects. JAMA 2013;310:2191-4.

18. Al-Bazzaz F, Grillo H, Kazemi H. Response to exercise in upper airway obstruction. Am Rev Respir Dis 1975;111:631-40.

19. Grillo HC, Donahue DM, Mathisen DJ, et al. Postintubation tracheal stenosis. Treatment and results. J Thorac Cardiovasc Surg 1995;109:486-92.

20. Geffin B, Grillo HC, Cooper JD, et al. Stenosis following tracheostomy for respiratory care. JAMA 1971;216:1984-8.

21. Smeltz AM, Bhatia M, Arora H, et al. Anesthesia for Resection and Reconstruction of the Trachea and Carina. J Cardiothorac Vasc Anesth 2020;34:1902-13.

22. Schieren M, Egyed E, Hartmann B, et al. Airway Management by Laryngeal Mask Airways for Cervical Tracheal Resection and Reconstruction: A Single-Center Retrospective Analysis. Anesth Analg 2018;126:1257-61.

23. Lang G, Taghavi S, Aigner C, et al. Extracorporeal membrane oxygenation support for resection of locally advanced thoracic tumors. Ann Thorac Surg 2011;92:264-70.

24. Hong $\mathrm{Y}$, Jo KW, Lyu J, et al. Use of venovenous extracorporeal membrane oxygenation in central airway obstruction to facilitate interventions leading to definitive airway security. J Crit Care 2013;28:669-74.

(English Language Editor: C. Betlazar-Maseh) 